\title{
TRABALHO: vazio e espoliação em Fifteen Million Merits (Black Mirror)
}

\section{Daniela Oliveira Ramos dos Passos} Paulo Roberto Barreto Caetano

\section{Resumo}

O artigo discute como se dá a espoliação e a subjugação do indivíduo no trabalho em Fifteen Million Merits (2011). Nesse episódio da série Black. Mirror, é possível ver uma indistinção entre jornada de trabalho e vida fora do labor, bem como se percebe um processo de espetacularização das singularidades do indivíduo, de modo a transformar em mercadoria os mais diversos aspectos da subjetividade num agudo processo de subjetivação e embotamento. O protagonista, para se desvencilhar das amarras, adota uma postura de pragmática abstenção, aparentemente. Tais características são comentadas a partir da noção de crítica ao capital e dos processos do trabalho desumanizador de Karl Marx, do disciplinamento dos sujeitos por E. P. Thompson; bem como de biopolítica de Michel Foucault e de corpo sem órgãos de Gilles Deleuze.

Palavras-chave: trabalho; espetáculo; Black Mirror.

\begin{abstract}
The article discusses how is the dispossession and subjugation of the individual through work on Fifteen Million Merits (2011). In this episode of Black Mirror series, you can see a lack of distinction between working hours and life outside of work as well if notices a spectacle process of the individual singularities, to transform merchandise various aspects of subjectivity an acute process of subjectivity and blunted. The protagonist, to disengage the shackles, adopts a posture of pragmatic abstention, apparently. These characteristics are commented from the notion of critique of capital and dehumanizing work processes of Karl Marx, in addition to disciplining the subjects by E. P. Thompson, as well as bio-politics of Michel Foucault and Gilles Deleuze's body without organs.
\end{abstract}

Keywords: work; spetacle; Black Mirror

TRABAJO: vacío y expoliación en Fifteen Million Merits (Black Mirror)

Resumen

El artículo describe cómo es el despojo y el sometimiento del individuo a través del trabajo en "quince millones de méritos" (2011). En este episodio de la serie Espejo Negro, se puede ver una falta de distinción entre las horas de trabajo y la vida fuera del trabajo, así si da cuenta de un proceso de espectáculo de las singularidades individuales, para transformar la mercancía de varios aspectos de la subjetividad un proceso agudo de la subjetividad y romo. El protagonista, para desenganchar los grilletes, adopta una postura de abstención pragmática, aparentemente. Estas características se comentan desde la noción de crítica del capital y los procesos de trabajo de deshumanización de Karl Marx, además de disciplinar a los sujetos por E. P. Thompson, así como la biopolítica de Michel Foucault y el cuerpo de Gilles Deleuze sin órganos.

Palabras clave: trabajo, espectáculo, Espejo Negro 


\section{FIFTEEN MILLION MERITS: ESTERILIDADE E ESPETÁCULO}

Quais atividades e relações sociais tendem a emancipar o indivíduo? Quais atividades, em vez de lobotomizar, tornariam alguém mais atento, feliz para com o entorno? Que satisfação o trabalho proporciona? Como se dão os dispositivos de controle no trabalho?

Como que sugerindo o oposto dessas perguntas, Fifteen Million Merits traz uma circunstância em que os personagens são submetidos a atividades tão repetitivas quanto insossas. Dentre elas, estão pedalar numa estática bicicleta ergométrica e assistir a vídeos idiotizantes (como de gags de gordofobia, depoimentos pasteurizados de cantores). O looping de atividades vazias acaba gerando pessoas entediadas, alienadas, cujos objetivos são tão pequenos quanto o leque de fazeres diários. Mesmo a atividade física não cumpre sua função básica (de estimular, com efeito), pois o pedalar é parcamente dosado, produzindo corpos pouco atléticos.

Esse cenário se dá numa situação lacunar: não se sabe como foram parar ali os personagens, quem os obrigou a estar nesse prédio fechado, com roupas padronizadas (um desbotado uniforme cinza que parece aludir à vestimenta na distopia orwelliana 1984). A lacunaridade em Fifteen Million Merits pode ser vista também na ausência de contextualização quanto à instituição que promove o regime de disciplinamento: não se sabe se se trata do Estado e/ou de uma instituição privada. Percebe-se, contudo, que ela adota procedimentos próximos àquilo que Foucault (2008, p. 14) chamou de "razão de Estado", o imperativo que o governante tem para usar da força estatal visando à manutenção do próprio poder. Isso pode ser visto no controle totalizante ${ }^{1}$ exercido sobre $\mathrm{o}$ indivíduo: a capitalização dos mais ínfimos detalhes e da subjetividade, a limitação do deslocamento, a imposição de atividades físicas tão incessantes quanto inócuas, formando assim corpos dóceis e embotados.

Poder-se-ia dizer que tal circunstância seria uma metáfora da vida no geral em que as pessoas têm que lidar com certas regras existentes a priori, num quadro de aparente liberdade. Sendo verossímil ou não, a situação mostrada causa intenso desconforto pela vacuidade das atividades, pelos mecanismos de construção de insossos desejos (sejam individuais ou coletivos). O sonho no episódio é matéria não só cooptada, mas também engendrada por algo "externo".

O desconforto ainda pode ser visto nas instalações: para além da assepsia de shopping center (que se dá não só com a pulsão de limpeza mas também com a sobriedade excessiva nas cores dos objetos e desconsideração para com curvas na arquitetura), a clausura impera nos quartículos onde ficam os habitantes desse "prédio". Este é uma curiosa fusão de academia, programa de auditório e hotel, representando, respectivamente, a domesticação dos corpos, o entretenimento raso mas agressivo, e a impossibilidade de criação de raízes simbólicas para com o espaço (diferentemente do que, por exemplo, uma casa usual permitiria em sua uma reconfortante decoração ao gosto do morador). Ali a responsabilidade pela educação vem da TV, com programas maçantes e rotineiros. Em todo ambiente clean não há sinal de livros; os diálogos são tão enxutos quanto insípidos - o que tem relação direta com o fato de os personagens em sua maioria não terem necessidade de contestar as "ordens e leis" desse local. O entretenimento distrai, aliena usando de estímulos visuais.

A comida integra também a ambiência asséptica: insossa, seca, parca, sem molho; pouco nutritiva e oriunda de uma máquina; exibida enquanto "imagem virtual" na máquina para só depois surgir como "coisa real", reforçando assim a virtualização vertiginosa no cotidiano; é, pois, a

\footnotetext{
${ }^{1}$ Essa ambição de um controle totalizante contém inequívocos traços do fascismo, o qual diz respeito a um Estado totalizante que busca (através de parcerias com empresas, através de arranjos legais) controlar o indivíduo em sua subjetividade (afetos, posicionamentos ideológicos), possibilidade de deslocamento físico, dentre outros.
} 
comida, então, desprovida da ideia de processo como, por exemplo, a própria pessoa lidar com os ingredientes e paulatinamente prepará-los.

Somado a essa limpeza excessiva, a hostilidade do regime ali instaurado se dá com a imposição de propagandas. Diferentemente do que costuma ser a regra no capitalismo, no episódio, há uma obrigatoriedade em visualizar os anúncios. A obrigação acaba sendo uma violência via estímulo visual e sonoro (com a exibição nas "paredes-telas" que formam cada quarto), e como era de se esperar, essa imposição acarreta uma repugnância em relação aos anúncios - obrigação ostensiva que acaba sendo inverossímil. Seria possível comparar essa cena com a lavagem cerebral perpetrada em Laranja Mecânica ${ }^{2}$, película em que o trabalho de colonização do inconsciente ${ }^{3}$ é também almejado.

A estrutura do quarto então, além de claustrofóbica e ostensiva, diz da relação do ser humano com a tecnologia: a informatização da vida se dá, no episódio, de forma acachapante; os quartículos tem não "apenas" as paredes como telas de TV, monitores de fora a fora, possuem telas em que funcionam menus para, por exemplo, compra de itens. Por meio desses menus, notase a presença do mercado o mais penetrante possível nas doses mais ínfimas: não se compra mais, por exemplo, uma bisnaga de creme dental, mas os gramas a serem usados em cada vez que se escova os dentes; a mercadoria cada vez mais precisada, calculada. A informatização intensa ocorre ainda pela interação do homem com a máquina: aquele não fala mais somente com outro humano, mas fala também com os aparelhos, criando vínculos novos.

Essa relação mais intensa para com o sistema socioeconômico fica mais ainda aguda quando ela se desloca de um produto ordinário (como a pasta de dente) para aspectos da subjetividade. Tendo a capacidade de se apropriar de tudo, o sistema socioeconômico vigente debruça-se sobre afetos, fazendo com que mesmo algo impalpável como o sentimento de raiva se torne produto a ser exposto e vendido, como ocorre com o protagonista. Bing Madsen revolta-se com a artificialidade daquele regime, e profere isso num ataque de fúria, o qual é cooptado habilmente e então transformado em atração "televisiva". Ou seja, mesmo a crítica feroz é apropriada pelo próprio sistema, fazendo-o recrudescer. A emblemática frase de Marx "Tudo que é sólido se desmancha no ar, tudo que era sagrado era profanado...” diz respeito não só ao poder de apropriação e mudança que o capitalismo exerce, bem como uma capacidade de corrupção, de rompimento. É possível dizer que o protagonista é corrompido com a proposta de esbravejar (mas é também possível dizer que não houve corrupção, e que o idealismo dele também era artificial, já que acaba aceitando o convite). Cabe destacar, que existe um processo de adaptação do sistema capitalista às eventuais mudanças da sociedade. Uma espécie de "evolução" (bem ao modo darwinista) na qual quem sobrevive não é somente o mais forte, mas aquele que consegue se adaptar melhor ao sistema (ou ao meio). Quando "algo sai do controle" o sistema rapidamente se organiza para também se adaptar às mudanças em curso ${ }^{4}$.

O esbravejamento de Madsen seria uma singularidade gestada em função da longa rotina de exercícios insossos e de entretenimento idiotizante. Essa usualidade é responsável pelos olhos sonolentos, pelos movimentos lentos do protagonista. Com pragmatismo e planejamento, o jovem trama como se dará a explosão: uma tentativa dúbia entre um suicídio e um atentado contra um jurado. O ineditismo da ação é habilmente aproveitado por outro jurado que vê na revolta um produto em potencial. Da ação (matar ou morrer), Madsen passa à fala; ora enérgica, ora convulsa, aparentemente autêntica, ele critica a falsidade do contexto, o predomínio do virtual em detrimento

\footnotetext{
2 Stanley Kubrick, 1971.

${ }^{3}$ Como se vê no momento em que Alex DeLarge é forçado a ver repetidamente determinadas cenas numa tela as quais têm como trilha a Nona Sinfonia, de Beethoven.

4 A social democracia e o Welfare State são exemplos práticos desse "novo capitalismo".
} 
do real, dentre outros. Black Mirror ${ }^{5}$ colhe muito de seus enredos em $A$ sociedade do espetáculo. Essa inversão (a predominância do virtual sobre o real) aproxima-se do que Guy Debord (1997) coloca como "mundo invertido", o verdadeiro seria o momento do falso. Não se faz aqui uma determinista dicotomia entre real e virtual, no qual aquele seria o verdadeiro, e este, o falso, até porque essas noções, na contemporaneidade se confundem. A ideia de falsidade diz respeito a uma artificialidade idiotizante.

Somado a isso, há o fato de que as performances no programa de auditório têm intenso apelo sentimental, e são vistas por uma grande plateia que muito se deixa impactar. As reações da audiência oscilam entre a catarse e o hipnotismo ${ }^{7}$, num estado de vigília consciente. Isso se coaduna com a ideia de que o espetáculo é sempre algo grandioso, indiscutível ${ }^{8}$; o que aparece é bom, o que é bom aparece, como coloca Debord (1997). A grandiosidade é, pois, não só a glamourização do objeto filmado mas também sua visibilidade temporária. O que poderia ser uma trinca no sistema acaba sendo um estratagema para fortificação dos mecanismos ali vigentes: incorporou-se até mesmo o que vai contra. Nada se perde; pouco se mantém sólido.

Frente a isso o aparente objetivo inicial é dissipado, e ocorre o que o autor de $A$ sociedade do espetáculo coloca no fragmento 14: o espetáculo não quer chegar a outra coisa senão a si mesmo. Essa recursividade calculada aponta para o efeito propositalmente estéril: nada desestabilizador brotaria da circunstância (nada pelo menos que venha a tirar o controle do poder vigente).

As ideias de Debord (1997) operam ainda numa lógica que ainda é muito dicotômica entre grande arte e entretenimento, como se essas duas possibilidades não pudessem se confundir, como se não fosse possível haver um produto que fosse espetacular, mercadológico e ao mesmo tempo apreciável estética e intelectualmente. Em vários momentos, a própria série aqui comentada pode gerar um efeito hipnótico-encantatório.

Outro ponto que chama a atenção no episódio diz respeito à vacuidade de que se investe Madsen. Devido à admiração (quiçá amor), ele doa seu patrimônio para que a cantora aspirante se realize. A plenitude da existência, a circunstância que o faria se sentir vivo de fato passa pela abnegação. A transferência funcionaria como uma herança que, contudo, em vez de se dar pelo laço biológico-legal, ocorre pelo arranjo afeto-legitimidade devido à afinidade eletiva. Da tradição passar-se-ia ao novo, ao outro, isto é, romper-se-ia com a tendência de manter o bem entre familiares, para então transferi-lo ao outro, a alguém de fora do clã. A morte, como coloca Derrida (2004, p. 12,14), ensejaria isso, lidar com a tradição e o novo, o que dicotomicamente efetuaria um distanciamento do passado, ainda que o homenageie. E o herdeiro, além de ter sua finitude atestada, estaria num duplo endividamento: acerca do que vem e do que virá.

Em Fifteen Million Merits, o peso dos créditos recebidos pode ser visto no olhar que a candidata, Abi Khan, lança ao protagonista quando pressionada a aceitar a proposta deturpadora: sair primordialmente da arte e ir para a pornografia. O canto seria um pretexto para espetacularizar o corpo, e a jovem é induzida a outra carreira. O episódio traz de modo ostensivo (e com alguma caricatura) o sistema econômico como trator de sonhos; eis aí a finitude. O momento de virada ocorre, pois, quando ao entrar em contato com o cerne do programa (uma epítome alegorizada das forças do capital) Abi cede à máquina de produção de subjetividades, de mercadorização de corpos. Concorrem nessa operação assédio dos jurados, a força expositiva da TV ${ }^{9}$, o fervor da multidão, a

\footnotetext{
${ }_{5}^{5}$ Cabe lembrar que a série é formada por episódios que guardam independência temática entre si, como se fossem contos, e não capítulos em sequência de uma novela.

${ }^{6}$ Fragmento nove.

${ }^{7} \mathrm{O}$ fragmento 18 coloca que o hipnotismo diante de imagens simplórias costuma ser uma reação ao espetáculo.

${ }^{8}$ Fragmento 12.

9 Fragmento 12.
} 
consciência alterada (devido ao uso de um alucinógeno). A aliança afetivo-idealista com Madsen é assim cortada; o vínculo vital e totalizante agora se dá com a "instituição", com o programa que Abi recebe.

Como se vê, o protagonista procura se desinvestir do capital (uma espécie de moeda digital) como forma de realizar um desejo que seria autêntico, o da cantora. Fracassada essa empreitada, encontra o desejo que seria autêntico: implodir o sistema em que está inserido. De modo obstinado, ajunta o "dinheiro-crédito", e o investe totalmente na inscrição do concurso. Novamente todas as posses são canalizadas de modo idealista num objetivo; é como se sugerisse que a despossessão fosse requisito para obter uma vida realizada, plena - uma caricatura idealista com ecos religiosos do desejo e da felicidade, como se estes pudessem ser alcançados de modo bruto, primevo, à revelia das forças do capital. Em suma, um purismo fadado ao fracasso, como o próprio episódio mostra com os dois personagens, cada um a seu modo, que participam da seleção.

Por um momento, essa despossessão que visa a uma atividade mais autêntica (ou algo que o valha) ganha contornos análogos ao conceito deleuziano de "corpo sem órgãos" (DELEUZE, GUATARI, 2008). Tirando o fato de este dizer respeito a uma condição nômade (o que está longe de ser o quadro em que vivem os personagens), essa noção pode ser vista no desejo de romper com uma programação "externa" que condiciona os corpos, induzindo-os à produção, o que retiraria o potencial revolucionário do corpo. O CsO seria, pois, uma fuga à instrumentalização de modo criar novas realidades, diferentes das que chegam, rompendo assim com um adestramento.

\section{VIDA CONTROLADA E CRÍTICA AO CAPITAL}

Fifteen Million Merits funciona também como uma crítica ao sistema capitalista, uma sociedade dividida em classes (status) em que algumas pessoas se veem pressionadas a trabalhar (pedalar) para conseguir "méritos" (ou moeda). Nesse caso, o termo trabalbo funciona não como algo "humanizador". Pelo contrário, partindo de uma análise marxiana, entende-se que:

O trabalho é antes de tudo, um processo entre o homem e a natureza, processo este em que o homem, por sua própria ação, medeia, regula e controla seu metabolismo com a natureza. Ele se confronta a matéria natural como uma potência natural [NaturmachA]. A fim de se apropriar da matéria natural de uma forma útil para a sua própria vida, ele põe em movimento as forças naturais pertencentes a sua corporeidade: seus braços e pernas, cabeça e mãos. Agindo sobre a natureza externa e modificando-a por meio desse movimento, ele modifica, ao mesmo tempo, a sua própria natureza. Ele desenvolve as potências que nela jazem latentes e submete o jogo de suas forças a seu próprio domínio. (MARX, 2013, p. 255).

Nessa passagem, Marx não trata do trabalho na forma como é concebido na história do tempo presente, o trabalho assalariado. Aqui, o trabalho é apresentado como a ontogênese humana, como a categoria fundante do desenvolvimento do ser social e, consequentemente, a construção do seu mundo, ou seja, da realidade social humana. O trabalho, portanto, cumpre a finalidade de produzir valores de uso destinado à satisfação de necessidade humanas e, ao mesmo tempo, conduz o ser que se humaniza e socializa. No trabalho, os homens e as mulheres "ganham a vida"; é o trabalho que lhes permite apropriar das coisas. (MARX, 2013).

No sistema capitalista, há uma fluidez no conceito de trabalho, de função. A complexidade do trabalho diminui, bem como a qualificação necessária para exercê-lo. O individualismo dos trabalhadores se desenvolve à medida que eles se tornam intercambiáveis. Ainda em uma análise marxiana, ao produzir objetos e objetivações (ou seja, mercadorias trocadas, a vida trocada em 
mercadorias), o trabalhador perde o domínio sobre o processo de trabalho. No sistema capitalista, os produtos do trabalho passam a ter valor de uso e valor de troca (mercadoria) e as relações sociais são relações entre coisas, e essas coisas são mercadorias.

Assim, o trabalho não seria um processo "natural", mas algo que é forjado, condicionado e socializado para torna-se parte variável do capital. Atores individualizados seriam colocados à disposição desse sistema, separados dos seus meios de produção e consequentemente de seus elos sociais. Em Fifteen Million Merits, "todos os dias", os personagens do episódio trabalham sozinhos, pedalando sem a necessidade de interagir com ninguém; buscam suas metas pessoais. Quanto mais tempo e dedicação oferecem, mais créditos ganham, para usufruir das mercadorias. Os momentos de atividades em seus dias são voltados para o trabalho. Pedalam o dia inteiro se distraindo com programas, jogos ou compras, perseguindo dinheiro e metas. Suas bicicletas abastecem de energia o sistema.

No episódio, também é perceptível a distinção social dos personagens: a classe alta (as personalidades da TV), a classe média (os que pedalam) e a classe mais baixa (os faxineiros, em geral, pessoas gordas que não conseguem pedalar o suficiente para garantir seus "méritos"). As pessoas "fora do peso padrão", ou seja, fora da chamada "forma", são retiradas das categorias de "proletárias" geradoras e consumidoras de energias/riquezas elétricas, e são realocadas na classe "lúmpen" de limpeza. Essa subclasse se diferencia dos ciclistas (um pouco mais atléticos, usando uniforme cinza), por serem obesos; vestem roupas "folgadas" na cor amarela. Além de sofrerem hostilidades por estarem "fora de forma", também são vistos como preguiçosos - incapazes de desenvolver os mesmos esforços que os demais "ciclistas" - realizando uma atividade pouco valorizada.

Nesse cenário, as relações físicas e pessoais são praticamente inexistentes. E quando há algum indício de demonstração afetiva, elas são logo destruídas como se vê na cena do pinguim de origami feito por Abi e dado a Madsen, presente que é jogado fora e descartado como lixo. Tal situação se torna uma das características de inibição da formação de grupos e/ou classes. Grupos, nesse sentido, seria a união de indivíduos que têm um aspecto social em comum, ou mesmo um senso de ligação, de integração e de identificação. A ideia de grupo inclui um sentimento muito forte de pertencimento e compromissos mútuos baseados em uma experiência comum e de acentuada interdependência. A interação social é tida como marcante e é mantida através de alguma forma de organização, no sentido de realizar ações conjuntas de interesse comum de todos os seus membros.

Como os personagens de Fifteen Million Merits não se reconhecem enquanto grupos, ou mesmo classes, as ações coletivas são inexistentes - o que contradiz a incorporação dos trabalhadores (atletas/ciclistas) ao processo político de manifestação de interesses, através de uma forte e intensa solidariedade de classe/grupo. O grupo de ciclistas (trabalhadores) é marcado pela individualidade. Não existe nesse ambiente uma classe significativa ou uma representação de classe. Há pouca empatia ou solidariedade.

Assim, para criar o compromisso com organizações sindicais, vistas como instrumentos de realização de interesses imediatos de nível individual ou de classe seria necessária

[...] a existência de um sentimento de "comunidade" partilhado por trabalhadores, definido como identidade própria, coexiste[nte] com a orientação instrumental que mapeia sua conduta social e política no ambiente de trabalho e

\footnotetext{
10 De acordo com o vocabulário marxista, Lumpenproletariado seria a população situada socialmente abaixo do proletariado, do ponto de vista das condições de vida e de trabalho, formada por frações miseráveis. Pessoas não apenas destituídas de recursos econômicos, mas também desprovidas de consciência política e de classe, sendo, portanto, suscetíveis de servir aos interesses da burguesia.
} 
fora dele. Este "coletivismo instrumental" não decorre primeiramente de mudanças ocorridas na estrutura ocupacional, mas de dimensões sociais e culturais mais amplas da história de vida do trabalhador, definindo o seu mapa interpretativo (PRATES, 1996, p. 4).

Ou seja, para que as organizações sindicais (trade-unions) tomem forma e tenham "poder" nas instâncias políticas e consigam "negociar" com o capital, é necessário o sentimento de pertencimento a uma classe. Sentimento esse que leve em conta as condições semelhantes de experiência vivida, que comparte da sensação coletiva de uma identidade comum e identifique outro(s) grupo(s) de homens e mulheres, da mesma formação social, como sendo de sua classe oponente. Tal sensação de pertencimento inexiste entre os personagens de Fifteen Million Merits.

Outro aspecto que chama a atenção no episódio é a notação do tempo e sua relação com mecanismos disciplinadores. Ali a medição temporal se dá, por exemplo, através de animações edênicas e infantilizantes. Exemplo disso é o desenho (animação) do galo-despertador num campo. E. P. Thompson (1998), em Tempo, disciplina de trabalbo e capitalismo industrial, discute como a mudança em perceber o tempo afetou a disciplina do trabalhador na Europa Ocidental no final do medievo. Era lugar-comum entre os anos de 1300 a 1650, "cronometrar" o cotidiano via natureza. De acordo com os Contos de Canterbury ${ }^{11}$ (século XIV), o galo ainda aparecia no seu papel imemorial de relógio:
Levantou o olhar para o sol brilhante
Que no signo de Touro percorrera
Vinte e tantos graus, e um pouco mais,
Ele sabia pela natureza, e por nenhuma outra ciência,
Que amanhecia, e contou com a voz alegre [...]
Bem mais confiável era o seu canto [do galo] no poleiro
Do que um relógio, ou o relógio da abadia.
(CHAUCER, Geoffrey apud THOMPSON, 1998, p. 268).

O trabalho, do amanhecer até o crepúsculo, podia parecer "natural", e a notação do tempo que se dava nesse contexto era descrita como orientação pelas tarefas. Mas orientar-se pelas atividades cotidianas campestres se tornava algo mais complexo nas situações em que se passou a empregar mão de obra fabril. À medida que o século XVII avançava, a imagem do mecanismo do relógio se expandia, até que com Newton, ela começou a tomar "conta do universo". E em meados do século XVIII, o relógio passou a fazer parte dos níveis mais íntimos, como as adaptações dos relógios de bolsos e/ou portáteis (THOMPSON, 1998).

Com a transição para a sociedade industrial, houve uma reestruturação mais rigorosa dos hábitos de trabalho: novas disciplinas, novos estímulos e uma nova natureza humana em que esses estímulos atuassem efetivamente. Por meio de uma cultura que poderia ir além das técnicas das manufaturas (divisão e supervisão do trabalho, multas, sinos, igreja, relógios, incentivos em dinheiro, ensino, escolas: formar novos hábitos etc.), houve a imposição de uma nova disciplina do tempo. A sociedade capitalista nascente acabou por moldar todo o tempo que deveria ser usado na produção e no consumo.

Tal fato é perceptível em Fifteen Million Merits, em que se vê um aspecto contemporâneo: a nebulosidade entre virtual e o chamado real (se é que é possível separar um do outro). Através dos

\footnotetext{
11 Os Contos de Canterbury, escritos entre 1386 e 1400, são permeados de lirismo e humor: trinta peregrinos - entre os quais se inclui o próprio autor, Geoffrey Chaucer - partem em romaria para a catedral de Canterbury e durante a viagem contam, cada um à sua maneira, uma história para entreter o grupo, mostrando as diversas facetas da vida medieval.
} 
diversos dispositivos tecnológicos (a representação do canto do galo para notação do tempo), as pessoas se afastam cada vez mais da natureza, trocando a paisagem natural (ou palpável) pela virtual. O tempo da natureza versus o tempo social condicionou a tecnologia à medição do período. A realização pessoal e as aspirações a uma mobilidade social passam a ser sugeridos como uma lista de "méritos" que o homem moderno (e agora o contemporâneo) busca(m). E nesse caso, o "cronometrar o tempo" faz toda a diferença, mesmo que seja em um formato virtual do "canto do galo".

A submissão a regulamentos constantes (tempo, leis, espaços) pode gerar o "indivíduo dócil", ou seja, disciplinado, que oferece funcionalismo, utilidade e habilidade. Aquele que está enquadrado no tempo e no espaço. Especificamente sobre o espaço, no episódio, é perceptível analisar o cenário de um local de clausura, limpo e asséptico. Nos dizeres de Foucault (1984), poderíamos classificá-lo como uma "arquitetura hierárquica" capaz de encaixar os "corpos" e submetê-los ao controle social, à disciplina, à ordem. Nesse espaço, o corpo social tornar-se-ia um elemento que se poderia colocar, mover, articular com os outros, reduzindo-o funcionalmente e inserindo-o em um "corpo-segmento" de um conjunto, no qual o indivíduo se articularia individualmente (FOUCAULT, 1984).

Em Fifteen Million Merits, no "cenário" em que os personagens trabalham/pedalam, há o espaço do "transparente", onde, de acordo com a noção foucaultiana do panóptico, todos(as) estariam submetidos a uma vigilância permanente, exaustiva e onipresente. Capaz de tornar tudo visível, o mando e o poder funcionariam perfeitamente. A permanente visibilidade asseguraria o fim da multidão "revolucionária" e valorizaria a individualidade, o ser visível, dócil e fácil de dominar. As pessoas estariam enquadradas no conjunto que foi articulado. O poder seria exercido a cada olhar, já que o fato de sempre ser visto manteria sujeito disciplinado (FOUCAULT, 1984).

Dessa forma, tal espaço se tornaria uma paisagem "naturalizada", palco de acontecimentos que nada operam. Na visibilidade do espaço, os corpos são organizados (ordenados) em "seu lugar" para serem vistos, vigiados, conforme uma vontade alheia. Essa situação não basta para formar comportamentos, mas pode ser através dela que venham a se desenvolver, pois nesse local a liberdade do espaço entraria em conflito com a liberdade do corpo.

Os corpos individuais se tornariam desligados dos lugares que passariam a transitar/trabalhar, perdendo ainda a noção de destino compartilhado e se tornariam desencorajados a se organizarem em grupos - fato reforçado pela valorização do virtual em detrimento do real. Os personagens vivem, pois, em função de predefinições, fazem poucas escolhas significativas. Seguem uma rotina dada, e quando ameaçam fugir dela (ou a ela), logo são cooptados pelo sistema.

Assim, a distopia vivida pelos personagens é fundada no individualismo, na falência do social. E o único caminho viável para sair desse ambiente "escravizante" seria pedalando, somando seus méritos e sonhando com um "ingresso dourado" para participar de um programa promissor e assim galgar uma "situação social" melhor (status) dentro desse sistema.

\section{CONCLUSÃO}

O episódio Fifteen Million Merits traz questões caras ao que se coloca sobre biopolítica e sobre capitalismo como produtor de subjetividades, visto que o próprio corpo e os desejos são mercadorizados. Nesse sentido, a produção de mercadorias pode ser tanto o produto da troca como a abstração "fria" da produção do trabalho, em que o trabalhador (o "ciclista", o faxineiro) não se reconhece em sua atividade rotineira, gerando alienação. Somado a isso, vê-se no episódio, 
por vezes de modo caricato, o trabalho em sua contemporânea dimensão de espetáculo e entretenimento, como instrumento para atenuar a vacuidade das atividades diárias.

Ainda que em alguns momentos a caracterização se torne inverossímil (como quando o protagonista é obrigado a ficar de olhos abertos frente a um anúncio), faz-se interessante pensar como a dimensão da aparente diversão se enraizou em ambientes como, por exemplo, o das chamadas startups, empresas em que, em nome da produtividade e da solução de problemas, podese, por exemplo, ouvir música, nadar em piscina de bolinhas, tomar cerveja - durante a jornada de trabalho, em nome da produtividade e da meta a ser batida. Ou seja, circunstâncias insólitas podem ser absorvidas visando a um resultado, inclusive alteradores da percepção. O ideal de superação, esse clichê, ganha um novo capítulo. E como não poderia ser diferente, a incidência sobre o corpo é, pois, incisiva, em função da demanda, a qual requer recursos vários para resolução.

O episódio também aborda o disciplinamento dos corpos, através do tempo de trabalho (relógio), da vigilância (um desdobramento do panóptico) e do espetáculo. Os personagens pedalam para conseguir a moeda de troca (o que dá um verniz meritocrático à situação), gerando energias para o sistema. Isso forma um sujeito gradativamente automatizado, alienado. Os personagens no episódio têm, pois, pouco tempo para pensar acerca do que produzem (não se reconhecendo no próprio trabalho), conseguindo assim questionar apenas parcamente o status quo, já que aspectos da subjetividade também são mercadorizados, fazendo do indivíduo um protótipo de ator nesse cenário - circunstância que o estimula egoicamente, num contexto de intensa cooptação e espetacularização.

\section{REFERENNCIAS}

DEBORD, Guy. A sociedade do espetáculo. Tradução Estela dos Santos Abreu. Rio de Janeiro: Contraponto, 1997.

DELEUZE, Gilles; GUATTARI, Félix. Como criar para si um corpo sem órgãos. In: Mil Platôs. v. 3. Tradução de Aurélio Guerra Neto et al. São Paulo: Ed. 34, 2008.

DERRIDA, Jacques; ROUDINESCO, Elizabeth. Escolher sua herança. In: De que amanhã: diálogo/Jacques Derrida; Elizabeth Roudinesco. Tradução André Telles. Rio de Janeiro: Jorge Zahar, 2004.

FOUCAULT, Michel. Nascimento da biopolítica. Tradução Eduardo Brandão. São Paulo: Martins Fontes, 2008. (Coleção Tópicos).

FOUCAULT, Michel. Vigiar e punir: nascimento da prisão. 3. ed. Petrópolis: Vozes, 1984. Terceira parte: Disciplina. p. 124-204.

MARX, Karl. O capital: crítica da economia política: livro I: o processo de produção do capital. Trad. Rubens Enderle. São Paulo: Boitempo, 2013.

PRATES, Antonio Augusto Pereira. Sindicato: organização e interesses na sociedade capitalista avançada. In: Revista Brasileira de Ciências Sociais, n. 2, out. 1996. p. 28-40.

STALLYBRASS, Peter. O casaco de Marx: roupa, memória e dor. Belo Horizonte: Autêntica. 2016.

THOMPSON, Edward Palmer. Tempo, disciplina de trabalho e o capitalismo industrial. In: Costumes em comum: estudos sobre a cultura popular tradicional. São Paulo: Cia. das Letras, 1998. p. 267-304. 


\section{Informações do(a)(s) autor(a)(es)}

Daniela Oliveira Ramos dos Passos

Faculdade de Educação da Universidade do Estado de Minas Gerais (FaE/UEMG)

E-mail: ddanipassos@gmail.com

ORCID: 0000-0002-3087-0694

Link Lattes: http://lattes.cnpq.br/9472302197930280

Paulo Roberto Barreto Caetano

Universidade Estadual de Montes Claros, Centro de Ciências Humanas $(\mathrm{CCH})$

E-mail:paulorcaetano@yahoo.com.br

ORCID: 0000-0002-0804-6551

Link Lattes: http://lattes.cnpq.br/9047576130682712 